\title{
Profile and Outcome of In-hospital Cardiac Arrest in Coronary Care Unit of a Tertiary Care Hospital
}

\author{
Prabir K. Das ${ }^{1}$, Shakil Ghafur ${ }^{2}$, Manzur Murshed ${ }^{3}$, Swadesh Kumar Charkovortty ${ }^{2}$ \\ ${ }^{1}$ Department of Cardiology, Cox's Bazar Medical College, Cox's Bazar, ${ }^{2}$ Dept. of Cardiology, 250 \\ Bedded Shahid Sheikh Abu Naser Specialized Hospital, Khulna, ${ }^{3}$ Dept. of Cardiology, Chittagong \\ Medical College, Chittagong
}

\begin{abstract}
:
Key word:

Cardiac arrest, ventricular tachycardia, ventricular fibrillation, pulseless electrical activity, asystole.

Background: In-hospital cardiac arrests are associated with poor survival despite basic and advanced life support measures. Objective of this study was to find out the profile and outcome of in-hospital cardiac arrest patients admitted to coronary care unit (CCU) of Chittagong Medical College Hospital.

Methods: This prospective observational study was done on 243 consecutive patients developing cardiac arrest in CCU of Chittagong Medical College Hospital during a period of 1 year. Baseline demographics, clinical data, such as mode of arrest, timing of the event, duration of resuscitation were recorded. Basic and advanced life support measures were given according to AHA guidelines. The main outcomes were death and survival to hospital discharge with or without severe neurological disability.

Results: There were 168 male and 75 female. Male:female ratio was 2.4:1.Mean age of the study

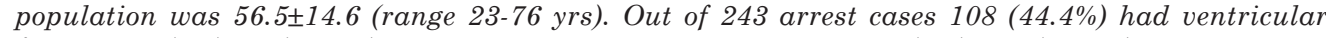
fibrillation(VF), 75(30.8\%) had pulseless ventricular tachycardia(VT), 51 (20.8\%) had pulseless electrical activity(PEA) and 9 patients (3.7\%) had asystole. Mean $\pm S D$ of time to defibrillation was $1.8 \pm 4.3 \mathrm{~min}$ (range 0 -30 min). Ninety eight $(40.2 \%)$ patients had a return to spontaneous circulation, $71(29.2 \%)$ survived up to 24 hours and only 46 (18.9\%) patients survived to hospital discharge. Out of the 183 patients with VF and pulseless VT, 42 (22.9\%) survived to hospital discharge. Survival following asystole and PEA were only $6.6 \%$ in each.

Conclusion: Only 18.9\% of cardiac arrest victims survived to hospital discharge. Initial cardiac arrest rhythm as VF and pulseless VT, a shorter time to defibrillation and location whether the event in monitored area were factors associated with a higher survival.
\end{abstract}

(Cardiovasc. j. 2016; 8(2): 123-127)

\section{Introduction:}

Cardiac arrests are medical emergencies requiring rapid decision making. In-hospital cardiac arrests are common and associated with poor survival despite immense life support measures to treat them. Average survival to hospital discharge after successful cardiopulmonary resuscitation (CPR) was about $15 \% .{ }^{1,2}$ It did not change markedly in spite of the remarkable therapeutic improvement over the last few decades. ${ }^{3-5}$ Patient related factors, such as demographic profile, pre-arrest morbidity, duration of resuscitation may be predictors of survival. ${ }^{6,7}$ Although there are many western studies on in-hospital cardiac arrest outcome, such studies on Bangladeshi patients are lacking. It is not clear whether the western data can be extrapolated to Bangladeshi populations. Hence, this study was done to examine the profile and outcome of patients developing cardiac arrest in CCU of Chittagong Medical College Hospital.
Methods:

This prospective observational study was done on patients developing pulseless cardiac arrest requiring chest compression, defibrillation or both, who were admitted in the coronary care unit of Chittagong Medical College Hospital from February 2013 to January 2014. Cardiac arrest was defined as sudden loss of consciousness with absence of palpable central pulse, apnoea and unresponsiveness. All admitted patients developing cardiac arrest who received CPR were included in the study.

Baseline profile of the study population including demographic data (age, sex), location of arrest (monitored and unmonitored ward), initial cardiac rhythm (VF, VT, asystole and PEA), timing of arrest, duration of resuscitation were obtained. For each case a case record form was filled in by the resuscitation team. A trained resuscitation team was available 24 hours a day, 7 days a week was responsible for identification of cardiac arrest and

Address of Correspondence : Dr. Shakil Ghafur, Dept. of Cardiology, 250 Bedded Shahid Sheikh Abu Naser Specialized Hospital, Khulna, Bangladesh, E-mail: ghafurshakil@gmail.com 
giving CPR. AHA guidelines for basic and advanced life support were followed for resuscitation of the cardiac arrest victims. ${ }^{8,9}$ An emergency kit including suction device, a bag valve mask for hand ventilation were available in CCU. Written consent from the patient's next to kin and clearance from the hospital ethical committee were obtained. The primary study outcome was survival to hospital discharge without severe neurological disability (defined as a CPC score of $\leq 2$ ).${ }^{10}$ Neurological status was evaluated using cerebral performance category (CPC) score. ${ }^{11} \mathrm{~A}$ CPC score of 1 is used to described patients with mild to no neurological disability, 2 for moderate disability, 3 for severe disability, 4 for coma or vegetative state and 5 for brain death.

\section{Statistical analysis:}

Result of normally distributed variables were presented as mean \pm standard deviation Mean and proportion of characteristics of participants were compared using student's t test and $\chi^{2}$ test. A p value of $<0.05$ was considered as significant. Statistical analysis was done with SPSS software version 18.0

\section{Results:}

There were 168 male and 75 female. Male: female ratio was $2.4: 1$. Mean age of the study population was $56.1 \pm 14.6$ (range 23-76 years).

\section{Table-I}

Demographic characteristics of the study population ( $n=243)$.

\begin{tabular}{llcc}
\hline Characteristics & & Number Percentage \\
\hline Sex & Male & 168 & 69.1 \\
& Female & 75 & 30.8 \\
Age(Yrs.) & $<40$ & 26 & 10.7 \\
& $40-49$ & 70 & 28.8 \\
& $50-59$ & 81 & 33.3 \\
& $60-69$ & 52 & 21.3 \\
Time of onset & Office hour & 14 & 5.7 \\
& Off office hour & 106 & 43.6 \\
Discovery status & Witnessed & 84 & 56.3 \\
at time of event & Monitored on ECG & 159 & 64.5 \\
Location of arrest & 170 & 69.9 & \\
Monitored area & Unmonitored & 73 & 30.1 \\
& area & & \\
\hline
\end{tabular}

Majority of arrest event (160; 65.8\%) resulted from acute coronary syndrome (unstable angina, non ST elevated MI and ST elevated MI). Congestive heart failure was the second commonest cause leading to the arrest event. Table II shows the underlying conditions leading to the arrest.
Table-II

Clinical Conditions leading to cardiac $\operatorname{arrest}(n=243)$.

\begin{tabular}{llcc}
\hline Diagnosis & & Number & \\
\hline ACS & STEMI & 108 & 43.6 \\
& NSTEMI & 17 & 6.9 \\
& Unstable angina & 35 & 14.4 \\
CHF & & 48 & 19.7 \\
Cardiomyopathies & & 21 & 8.6 \\
Pr.arrhythmias & & 9 & 3.7 \\
CV Procedures & CAG & 3 & 1.2 \\
& Pericardiocentesis & 2 & 0.8 \\
\hline
\end{tabular}

Associated co-morbid conditions prior to the arrest among the patients were as follows:

Table-III

Co-morbidities of the study population $(n=243)$.

\begin{tabular}{lcc}
\hline Co-morbid conditions & Number & Percentage \\
\hline Renal insufficiency & 14 & 5.7 \\
COPD & 11 & 4.5 \\
DM & 23 & 9.4 \\
CVD & 6 & 2.4 \\
Malignancy & 1 & 0.4 \\
Sepsis & 4 & 1.6 \\
Electrolyte disturbance & 3 & 1.2 \\
\hline
\end{tabular}

Therapeutic interventions undertaken before the event are shown in table IV

Table IV

Therapeutic interventions done during the CPR $(n=243)$.

\begin{tabular}{llcc}
\hline Interventions & & \multicolumn{2}{c}{ Number Percentage } \\
\hline Vascular access & & 243 & 100 \\
ECG monitoring & & 243 & 100 \\
Pulse oxymetry & & 13 & 5.3 \\
i.v. vasoactive & Epinephrine & 103 & 42.3 \\
agents: & & \multicolumn{2}{c}{} \\
& Dopamine & 55 & 22.6 \\
& Atropine & 138 & 56.7 \\
& Dobutamine & 34 & 13.9 \\
i.v. anti- & Nor-epinephrine & 13 & 5.3 \\
arrhythmics & Lignocain & 142 & 58.4 \\
Temporary pacing & Amiodarone & 41 & 16.8 \\
Pericardiocentesis & 07 & 2.8 & \\
\hline
\end{tabular}

All patients had vascular access with i.v.cannula and all had an ECG monitored. Nearly two third subject 183 patients $(75.2 \%)$ received i.v. antiarrhythmic agents. One hundred forty two (58.4\%) received Lignocain and 41(16.8\%) received i.v. Amiodarone. One hundred three (42.3\%) patients received Epinephrine as vasoactive agent during defibrillation with persistent VF. Intravenous atropine was administered in 138 (56.7\%) patients, including those with asystole, 
PEA and VF cases developing bradycardia at late phase of resuscitation.

Cardiac rhythm leading to the cardiac arrest are shown in table V. Two third of arrest (183; 75.2\%) were due to shockable arrhythmia i.e. VF and pulseless VT.

Table-V

Electrocardiogrphic diagnosis of Cardiac arrest $(n=243)$.

\begin{tabular}{lcc}
\hline Category & Number & Percentage \\
\hline Ventricular fibrillation & 108 & 44.4 \\
Pulseless V.T & 75 & 30.8 \\
PEA & 51 & 20.8 \\
Asystole & 09 & 3.7 \\
\hline
\end{tabular}

The time interval from initial recognition of arrest and application of D.C. shock (i.e. time to defibrillation) is shown in Fig-1. Mean \pm SD of the time of defibrillation was $1.8+4.3 \mathrm{~min}$ (range 0-30 $\min )$.

Only 11 patients (4.5\%) received early defibrillation (i.e. within $2 \mathrm{~min}$.).A delayed time to defibrillation was recorded in the rest 232 patients (95.3\%). Out of them 15 patients $(6.1 \%)$ had a defibrillation time of $3 \mathrm{~min}$. and 192 patients(79\%) had defibrillation time $>5 \mathrm{~min}$. The time interval between arrest and defibrillation is shown in fig.1.

Table-VI

Number of shocks delivered for defibrillation $(n=243)$.

\begin{tabular}{lcc}
\hline No. of shocks & Number & Percentage \\
\hline 1 & 16 & 6.5 \\
2 & 77 & 31.5 \\
3 & 93 & 38.2 \\
$4+$ & 57 & 23.4 \\
\hline
\end{tabular}

Total time of resuscitation undertaken for the subjects is shown in table 7. In unresponsive cases CPR was continued for at least 1 hour before declaring the patients as having brain death.

Table-VII

Duration of resuscitation ( $n=243)$.

\begin{tabular}{lcc}
\hline Time(min) & Number & Percentage \\
\hline d"15 & 48 & 19.7 \\
$16-35$ & 59 & 24.2 \\
$>35$ & 136 & 55.9 \\
\hline
\end{tabular}

One single shock was successful to defibrillated in $16(6.5 \%)$ patients. More than four successive shock was applied in 57 (23.4\%) patients. Total numbers of shocks delivered are shown in table VII. Survival status of the arrest victims are shown in table VIII.

Table-VIII

Survival status of the study population( $n=243)$.

\begin{tabular}{lcc}
\hline Survival Stage & Number & Percentage \\
\hline ROSC & 98 & 40.2 \\
At. 24 hrs & 71 & 29.2 \\
At. discharge & 46 & 18.9 \\
\hline
\end{tabular}

Immediate CPR success was defined as the return of spontaneous circulation (ROSC) persisting for a minimum of 20 min., was found in 98 (40.2\%) patients. Out of the subjects with ROSC, $71(29.2 \%)$ subjects survived upto 24 hours. Finally, 46(18.9\%) survived to hospital discharge. Average hospital stay for those who survived was 10.3 days compared with 1.3 days for those who died in the hospital after resuscitative measures undertaken. Overall survival to hospital discharge according to index event leading to the arrest is shown in table IX.

Table-IX

Index event and survival to hospital discharge $(n=46)$.

\begin{tabular}{lcc}
\hline Event & Number & Percentage \\
\hline Ventricular fibrillation & 23 & 50.0 \\
Pulseless VT & 19 & 41.3 \\
Asystole & 02 & 8.7 \\
PEA & 02 & 8.7 \\
\hline
\end{tabular}

When the first shock was delivered within 5 min the survival rate at discharge was $25.4 \%$ (13 of 51) vs $17.1 \%$ (33 of 192$)$ when it was $>5 \min (p<0.01)$. Neurological outcome of the survivors at discharge were generally good. Ninety five percent of patients were in post arrest CPC score 1-2 category

Table-X

CPC score at discharge $(n=46)$.

\begin{tabular}{lcc}
\hline CPC score & Number & Percentage \\
\hline 1(good ) & 35 & 76.0 \\
2(mild disability) & 09 & 19.6 \\
3(moderate disability) & 02 & 4.4 \\
\hline
\end{tabular}




\section{Discussion:}

In this prospective, observational study of 243 inhospital cardiac arrest cases, male dominated (69\%) and vast majority of the arrest victims were middle aged and elderly. The 24 hour survival rate was $29.2 \%$ and survival rate at discharge was $18.9 \%$ Survival rate decreased with increasing age, increasing time to defibrillation, increasing duration of resuscitation and were particularly low following PEA and asystole. These data do not differ greatly from those in Europe and North America. ${ }^{12,13}$ They found the same as $25.0 \%$ and $15.9 \%$ respectively. Various studies on in-hospital cardiac arrest shows that age, mode of cardiac arrest, time to defibrillation, duration of arrest are key predictors of survival. ${ }^{14,15}$ Although debate continues regarding the degree to which these and other predictors influence survival. Several studies reported greater survival to discharge rate which may be related to a difference in inclusion/exclusion criteria and subjects with pre arrest co morbid conditions. ${ }^{5,16}$ In this study nearly two third patients received i.v. antiarrhythmic agent. One hundred forty two (58.4\%) received Lignocaine and 41(16.8\%) received i.v. Amiodarone. Lignocaine was used almost twice as often as i.v. Amiodarone here. ALIVE (Amiodarone vs Lignocaine in prehospital refractory VF Evaluation) clinical trial of cardiac arrest in the prehospital setting demonstrated improved survival to hospital admission in shock refractory VF patient who received Amiodarone. ${ }^{17}$ The CALIBRE trial demonstrated that routine use of Lignocaine for treatment of VF/VT arrest is no better than placebo. ${ }^{18}$ The AHA advanced cardiac life support guidelines state that either epinephrine or vasopressin can be used as a first line vasopressor after defibrillation attempts in persistent VF. We used only Epinephrine in 103 (42.3\%) of our patients. A significant higher number of patients had their arrest detected in monitored area; 170 (69.9\%) vs. 73 (30\%); p<0.01. Still, 232 (95.3\%) patients had delayed time to defibrillation (>5 min), a delay that exceeds guidelines based recommendations. ${ }^{19}$ This suggests that a delay in rhythm recognition and subsequent application of D.C. shock might have happened. Patients with delayed defibrillation were significantly less likely to survive to hospital discharge. We found a graded association between poorer survival and longer time to defibrillation. This observation reinforces the rationale for shortening the time to defibrillation as much as possible to maximize the effectiveness of resuscitation. Asystole and PEA are often considered fatal events. We found $22.2 \%$ of asystole (2 out of 9 ) and 3.9\% (2 out of 51) of PEA survived to hospital discharge with good neurological outcomes. In a meta-analysis by Saklayen $\mathrm{M}$ et $\mathrm{al}^{20} 5.3 \%$ and $4.2 \%$ of patients with asystole and PEA arrests respectively were discharged from hospital alive. Improved survival with asystole arrest patients in our study may be the result of increased use of monitoring, early recognition and intervention. The relationship between defibrillation time and survival confirm the findings of other investigators that have shown a relationship between defibrillation time and survival. ${ }^{21}$ In our study 106 (43.6\%) patients had their event during office hour and 137 (56.3\%) during off-office hours. Thus there was no significant value difference between the time of occurrence of cardiac arrest but a significant relationship found between the monitored and unmonitored area events $(69.9 \%$ vs $30.1 \%$, $\mathrm{P}<0.0001)$. Thus the response time may be related in part to the emergent availability of trained medical professional, access to defibrillation equipment and delays in recognition of a ventricular arrhythmia.

Although the study findings are relevant to understanding of in-hospital cardiac arrest resuscitation and survival in Bangladesh perspective it has some limitations. A single center study on small sample size for a short period (1 year) and lack of follow up highlight the need for further studies to identify population at risk and predictors of survival after in-hospital cardiac arrest.

\section{Conclusion:}

The study provides important observational data on in-hospital cardiac arrest and it's outcome. Decreasing the time to defibrillation and appropriate institution of CPR may improve inhospital outcome in cardiac arrest. The present study may provide insight for further study on inhospital arrest.

\section{Conflict of Interest - None.}

\section{References:}

1. Cooper S,Evan C.Resuscitation predictor scoring scale for in-hospital cardiac arrests. Emerg Med J 2003:20:6-9. 
2. Utstein Style Writing Group, Recommended guidelines for reviewing,reporting and conducting research on inhospital resuscitation :the in-hospital Utsteinstyle. Ana Emer Med 1997 :29:650-679.

3. Fitzerald JD, Wenger NS, Catiff RM, et al. Functional status among survivors of in-hospital cardiopulmonary resuscitation. Arch Intern Med 1997:157:72-76.

4. Brindly PG, Markland DM, Mayers J, et al. Predictors of survival following in-hospital adult CPR.CMAJ 2002:167:348-380.

5. Pedbury M, Kaye W, Ornalo J, et al. Cardiopulmonary resuscitation of adults in the hospital: a report of 14720 cardiac arrests from the National Registry of cardiopulmonary resuscitation. Resuscitation 2003:58(3):297-308.

6. Ballew KA, Philbrick JT, Caven DE, Schorling JB. Predictors of survival following in-hospital cardiopulmonary resuscitation: a moving target. Arch Intern Med 1994; 154:2426-2432.

7. Albert CM, Mc Govera BA, Newell JB, Ruskin JN. Sex difference in cardiac arrest survivors. Circulation 1996 :93:70-76.

8. 2005 American Heart Association guidelines for cardiopulmonary resuscitation and emergency cardiovascular care. Circulation 2005:112:IVI-203

9. 2005 International concensus on Cardiopulmonary Resuscitation and Emergency Cardiovascular care. Science with Treatment Recommendations Part I:Introduction, Resuscitation 2005;67:181-186.

10. Chan PS, Krumholz AM, Nicol G, Nallamothu SK. Delayed time to defibrillation after in-hospital cardiac arrest. N Engl J Med Jan 3:2008 358(1):9-17.

11. .Jannett R, Bond M. Assessment of outcome after severe brain damage. Lancet Mar1,1975 ; 1(705):480-484.
12. Herlitz J. Bang A, Alsen B, Aune S. Characteristics and outcome among patients suffering from in hospital cardiac arrest in relation to the interval between collapse and CPR. Resuscitation 2002; 53(2): 127-133

13. Simon C, Mohsen J, Glenda C. A decade of in hospital resuscitation outcome and prediction of survival. Resuscitation 2006 ; 68:231-237.

14. Brinding PG, Maneland DM, MayersI, Kuly Oglanis DJ. Predictors of survival following in- hospital adult cardiopulmonary resuscitation. CMAJ 2002; 167: 343-348.

15. Cooper S, Cada J. Predicting survival in hospital cardiac arrests: resuscitation survival variables and training effectiveness. Resuscitation 197;35:17-22.

16. George A, Folk B, Creceling P, Barfon C. Pre-arrest morbidities and other correlates of survival after in hospital cardiopulmonary arrest. Am J Med 1989;87: 28-34

17. Dorian P, Cass D, Schwartz B, et al. Amiodarone as compared with lidocaine for shock - resistant ventricular fibrillation. N Eng J Med 2000; 346: 884-90

18. Tunstall - Pedoc H, Woodward M, Chermberlain D, Lidocaine and bretylium in resistant ventricular fibrillation. Eur Heart $J$ 2001; 22:449

19. Cummins RO, Ornato JP. Improving survival from sudden cardiac arrest: the "chain of survival"concept: a statement for health professionals, from the advanced cardiac life support subcommittee and the emergency cardiac care committee. American Heart Association. Circulation 1991; 83:1832-1847.

20. Suklayen M, Liss H, Markert R. In-hospital cardiopulmonary recitation: survival in hospital and literature review. Medicine 1995; 74:163-175.

21. Skrifars MB, Rosenberg PK, Finnep, et al. Evaluation the in-hospital Utsteintemplet in cardiopulmonary resuscitation in secondary hospitals. Resuscitation 2003; 56:275-282. 